artículos no derivados de proyectos de investigación 



\section{Abandono legislativo del objetivo de alcanzar la independencia en la auditoría de cuentas}

doi:10.11144/Javeriana.cc15-37.alod

Miguel Ángel Villacorta-Hernández

Profesor, Universidad Complutense de Madrid, UCM.

Doctor en contabilidad, UCM. Doctor en derecho mercan-

til, Universidad Carlos III, Madrid, UC3M.

Correo electrónico: mianvi@ucm.es 
Resumen La cualidad de independencia constituye la característica fundamental que deben poseer los auditores de cuentas anuales en el ejercicio de su actividad; hasta tal punto de que la existencia de esta actividad carece de sentido, si no es desempeñada por profesionales independientes. En este trabajo se analizan las ventajas y desventajas de las posibles medidas para garantizar la independencia del auditor. Para ello se analiza lo previsto por la US Securities Exchange Commission, SEC, la Ley Sarbanes-Oxley, las Directivas Europeas y la legislación española; no obstante, sus conclusiones pueden ser extendidas a países de América Latina, entre ellos Colombia.

La conclusión de la investigación es que la tibieza y las equivocaciones en la regulación internacional son el principal escollo para alcanzar un nivel alto de independencia en el trabajo del auditor.

Palabras clave autor: auditoría externa; escepticismo profesional; independencia; directiva europea

Palabras claves descriptor: auditoría financiera; auditores-responsabilidad social; auditoría de cuentas anuales

Códigos JEL: M 42, M 48

\section{Legal Abandon of the Purpose of Attaining Independence in the Audit of Accounts}

\footnotetext{
Abstract Independence as a quality constitutes the essential characteristic that account auditors of annual accounts must have in carrying out their activity, up to the point that the existence of this activity would not make any sense if it were not be performed by independent professionals. In this work we analyze the advantages and disadvantages of the possible measures to guarantee the independence of the auditor. For this we analyze the provisions of the US Securities Exchange Commission, SEC, the Sarbanes-Oxley Law, the European Guidelines and the
}

Spanish law. However, the conclusions may be extended to Latin American countries, Colombia among them. The conclusion of this research is that tepidity and mistakes in the international regulations are the main obstacle to attain a high level of independence in the work of the auditor.

Key words author: external audit; professional skepticism; independence; European guideline

Key words plus: financial auditing; auditors - malpractice; auditing

\section{Abandono legislativo do objetivo de alcançar a independência na auditoria de contas}

Resumo A qualidade de independência constitui a característica fundamental a possuir os auditores de contas anuais no exercício da sua atividade, até tal ponto que a existência desta atividade carece de sentido, se não é desempenhada por profissionais independentes. Neste trabalho analisam-se as vantagens e desvantagens das possíveis medidas para garantir a independência do auditor. Para tal é analisado o previsto pela US Securities Exchange Commission, SEC, a Lei Sarbanes-Oxley, as Diretorias Europeias e a legislação espanhola; não obstante, suas conclusões podem ser estendidas para países da América Latina, entre eles a Colômbia. A conclusão da pesquisa é que a fraqueza e os erros na regulamentação internacional são o principal escolho para alcançar um nível alto de independência no trabalho do auditor.

Palavras-chave autor: auditoria externa; cepticismo profissional; independência; diretoria europeia

Palavras-chave descritor: auditoria financeira; auditores - responsabilidade profissional; auditoria 


\section{Independencia del auditor}

El escepticismo profesional es considerado "como la piedra angular de la auditoría" (García-Benau, Zorio-Grima \& Novejarque-Civera, 2013, p. 236). El Parlamento Europeo y el Consejo de la UE (Comisión Europea, 2011a, art.

15) define el escepticismo profesional como "la actitud que implica mantener una mente inquisitiva y alerta ante cualquier circunstancia que pueda apuntar a una posible incorrección debida a error o fraude, y examinar críticamente la evidencia en auditoría”.

Este escepticismo "se consigue con la aplicación de su criterio profesional más la independencia del auditor" (Comisión Europea, 2010; Parlamento Europeo, 2011, p. apartado 23).

La cualidad de independencia constituye la característica fundamental que deben poseer los auditores de cuentas anuales en el ejercicio de su actividad. Tanto es así que la existencia de esta actividad carece de sentido, si no es desempeñada por profesionales independientes (Flint, 1988, p. 55). La doctrina se ha manifestado al respecto con afirmaciones rotundas: “(...) solo manteniendo la posición de independencia están en condiciones de servir con propiedad a quienes confían en ellos” (Cook \& Winkle, 1987, p. 65), “(...) a menos que el auditor sea independiente, la opinión que emita no será más fiable que los estados preparados por la dirección" (Stettler, 1977, p. 5). Para el American Institute of Certified Public Accountants (AICPA, 1996, ET 52.011), "La independencia ha sido siempre (...) la piedra angular de su estructura filosófica. A pesar de lo competente que pueda ser cualquier auditor, su opinión sobre los Estados Financieros tendría poco valor para aquellos que confían en él (...) si no mantuviese su independencia”. El Parlamento Europeo (2011) subraya que "en la calidad de la auditoría la independencia del auditor juega un papel fundamental".

La independencia del auditor no tiene una definición inequívoca por ser un concepto indeterminado y difícilmente observable empíricamente. Pese a lo anterior, hay una definición doctrinal clásica, admitida de forma generalizada, válida como primera aproximación: “(...) la probabilidad de que el auditor informe de un error o anomalía que haya descubierto" (Watts \& Zimmerman, 1983, p. 614).

La segunda norma de las Normas Técnicas de Carácter General, emitida por el Instituto de Contabilidad y Auditoría de Cuentas (ICAC), define la independencia como "una actitud mental que permite al auditor actuar con libertad respecto a su juicio profesional, para lo cual debe encontrarse libre de cualquier predisposición que limite su imparcialidad en la consideración objetiva de los hechos, así como en la formulación de sus conclusiones".

La independencia puede definirse desde una perspectiva subjetiva u objetiva. La subjetiva es aquella que viene dada por el estado mental del auditor; “(...) conceptos tales como honradez, integridad y objetividad para valorar la información contable y financiera definen esa independencia subjetiva" (Sahuquillo, 2008 , p. 2). El problema es que las investigaciones efectuadas (Firth, 2002) concluyen que la independencia real es muy difícil (si no imposible) de observar en la práctica, por lo que surge la independencia objetiva. La independencia 
objetiva, que tuvo su origen en las normativas anglosajonas basadas en el common law, está relacionada con la dimensión de parecer independiente, al centrar el análisis en el concepto de apariencia de independencia.

El cumplimiento, por parte de los profesionales, del deber de independencia está condicionado a que los usuarios de esta actividad así lo perciban y, para ello, el auditor debe ser independiente "de forma real" e independiente "en apariencia" (Titard, 1971; DeAngelo, 1981; Gul, 1989, p. 48; Ruddock, Taylor \& Taylor, 2011).

La legislación que recoge por primera vez la importancia de "parecer independiente", además de la lógica "ser independiente", es la Statements on Auditing Standards (SAS, 1973) estadounidense.

En la actualidad, los organismos estadounidenses se basan exclusivamente en la independencia objetiva. Tanto es así que la definición de independencia establecida por la que tiene su origen en la estadounidense Securities and Exchange Commission (SEC, 2011) no hace referencia en ningún momento a aspectos que tengan relación con la independencia en su vertiente real: “(...) no se considera a un auditor independiente con respecto a un cliente en particular si un inversor razonable, con conocimiento de todos los aspectos relevantes y circunstancias, concluiría que el auditor no es capaz de llevar a cabo su trabajo con juicio imparcial y objetividad".

En España, se requería exclusivamente la necesidad de "ser independiente", hasta el artículo 51 de la Ley 44/2002, que incluyó la necesidad de "parecer independiente". La Ley 44/2002, de 22 de noviembre, de Medidas de Reforma del Sistema Financiero (BOE, 23 de noviembre de
2002), en su artículo 51, modificó el artículo 8 de la Ley de Auditoría de Cuentas, LAC, dando como resultado que "los auditores de cuentas deberán ser y parecer independientes en el ejercicio de su función, (...) debiendo abstenerse de actuar cuando su objetividad en relación con la verificación de sus documentos contables correspondientes pudiera verse comprometida".

La definición en la legislación española ha virado de nuevo, pues en la actualidad ha desaparecido la afirmación "debe parecer" independiente y se limita a afirmar de nuevo que "debe ser" independiente. El artículo 8 de la Ley 12/2010 establece que "Los auditores de cuentas y las sociedades de auditoría deberán ser independientes, en el ejercicio de su función, de las entidades auditadas, debiendo abstenerse de actuar cuando su independencia en relación con la revisión y verificación de los estados financieros u otros documentos contables pudiera verse comprometida. Los auditores de cuentas y las sociedades de auditoría deberán abstenerse de participar en el proceso de toma de decisiones de la entidad auditada en los términos previstos en el apartado 8.3 de la Ley 12/2010", lo cual coincide con la redacción del punto 1 del artículo 12 del Texto Refundido de la Ley de Auditoría de Cuentas, que entró en vigencia el 3 de julio de 2011.

\begin{tabular}{lll}
\hline & \multicolumn{1}{c}{$\begin{array}{c}\text { Estados } \\
\text { Unidos }\end{array}$} & \multicolumn{1}{c}{ España } \\
\hline Parecer & SEC & - \\
Parecer y ser & SAS 1 & Ley 44/2002 \\
Ser & - & Ley 12/2010 \\
\hline
\end{tabular}

Tabla 1. Dimensión de la definición de independencia en la legislación española y estadounidense Fuente: elaboración propia 
Aunque la búsqueda de la independencia del auditor con la empresa auditada siempre ha sido considerada como una cualidad fundamental para el desarrollo de la labor de revisión contable, las medidas para fomentarla crecieron a partir de la cadena de escándalos por irregularidades contables y actuaciones gerenciales fraudulentas, que comenzó con los casos Enron-Andersen en 2001 y Parmalat en 2003. Según los estudios de Deborah L. Lindberg y Frank D. Beck (2003) y Eduardo Marcelo, Zhang Tao y Billy Carl Moore (2002), las percepciones de los usuarios sobre el cumplimiento de la cualidad de independencia por parte de los auditores se vieron mermadas tras la quiebra de Enron-Andersen.

Este trabajo analiza las ventajas y desventajas de las posibles medidas para garantizar la independencia del auditor y observar si se están tomando los pasos adecuados. Para ello, se examinan los desarrollos normativos internacionales, con especial referencia a la regulación comunitaria:

- Libro Verde. Política de auditoría: lecciones de la crisis (Comisión Europea, 2010).

- Resolución del Parlamento Europeo de 13 de septiembre de 2011 sobre Políticas de auditoría: lecciones de la crisis (Parlamento Europeo, 2011).

- Propuesta borrador de Directiva del Parlamento Europeo y del Consejo (Comisión Europea, 2011b), por la que se modifica la VIII Directiva 2006/43/CE (Parlamento Europeo y Consejo de la UE, 2006).

- Propuesta de Reglamento del Parlamento Europeo y del Consejo sobre las auditorías de las entidades de interés público (Comisión Europea, 2011a).

- Dictamen del Comité Económico y Social Europeo (CESE) emitido el 16 de junio de 2011 (CESE, 2011).

Entre las medidas para aumentar la independencia del auditor con la empresa auditada, destacamos tres: (a) mejorar el control del trabajo del auditor, (b) fijar incompatibilidades con otras actividades complementarias (limitación de actividad) y (c) establecer la rotación obligatoria (limitación temporal).

\section{Mejora del control del trabajo del auditor}

Dependiendo del país, el control del trabajo del auditor se realiza por medio de un organismo independiente o por una autorrevisión por parte de las empresas auditoras.

La primera medida consiste en mejorar el control del trabajo del auditor, si en un futuro se demuestra que los niveles de independencia han disminuido sustancialmente. En este caso, sería necesario profundizar en soluciones que rompan con la actual relación cliente-auditor, que dificulta la independencia por la propia esencia del negocio.

Con el sistema actual de relación cliente-auditor, la auditoría nunca podrá ser independiente del todo por la propia esencia del negocio. La Ley somete a las empresas a un experto independiente, nombrado por la sociedad auditada. El análisis económico de esta relación contractual provoca dudas sobre la independencia del auditor, por la ley social insoslayable de "quien paga manda". 
El problema se acentúa porque en la actualidad se ha producido una marcada captación de los auditores de cuentas, por las sociedades auditadas. Esto puede llevar a los auditores a convertirse en servidores de las empresas que auditan, para asegurarse la renovación de sus contratos y el progresivo incremento de su retribución global por servicios de auditoría, valoraciones de los activos y pasivos según las normas contables, consultoría, asesoramiento legal y asesoramiento fiscal.

Ante la eventual pérdida de independencia pueden valorarse cuatro soluciones para llevar a cabo mejoras en el control. La primera es la revisión tutelada, como la del ICAC en España. La segunda es una revisión de auditor a auditor, como lo señala la Recomendación de la Comisión, del 15 de noviembre de 2000 sobre el control de la calidad de la auditoría legal en la Unión Europea (DOUE, L 91, de 31 de marzo de 2001, requisitos mínimos, punto 2, Metodología). Este procedimiento debe ir unido a la fijación de un plazo legal límite en que una firma de auditoría puede auditar a una misma sociedad, ya que de este modo sabrá que su trabajo será sometido al juicio de la firma de auditoría que la suceda. La tercera es que los auditores sean privados pero un organismo público (en el caso español, de ámbito comunitario) designe al auditor a cada empresa auditada por turnos rotatorios, teniendo en cuenta la dimensión y la capacidad del trabajo de cada auditor. Esta alternativa es desechada por la Resolución del Parlamento Europeo (Parlamento Europeo, 2011, apartado 23), la cual descarta que el nombramiento de los auditores sea por un tercero distinto de la empresa auditada, que es la que los remunera. La cuarta solución es crear un organismo de supervisión independiente, de carácter público, que se encargaría de auditar a todas las sociedades.

De momento, no recomendamos la adopción de medidas a largo plazo porque, aunque pueden mejorar la independencia y abrir nuevos mercados en el exterior, irían en contra de la eficiencia de los procedimientos de auditoría. La principal desventaja de que un organismo público designara a los auditores privados es que produciría efectos negativos en el mercado, porque los turnos se acercarían a ser automáticos, independientemente de la eficiencia de la firma. Por su parte, la creación de un organismo público que audite directamente eliminaría los beneficios que genera la competencia empresarial y disminuiría las inversiones (incluso en capital humano) para mejorar los procedimientos de auditoría.

\section{Limitación de actividad}

La segunda medida consiste en fijar incompatibilidades entre la actuación del auditor y la posibilidad de ejercer simultáneamente otras actividades complementarias. La fijación o no de estas actividades es fundamental en estos momentos, cuando está generalizada mundialmente la aplicación de las normas del International Accounting Standards Board (IASB), directamente o por medio de la aproximación de las legislaciones contables locales a ellas, por ejemplo PGC 2007 y PGC-PYMES. Las normas del IASB incluyen criterios de valoración económicos como el fair value, coste amortizado, BlackScholes o métodos de valoración de opciones, 
que se apartan de los criterios jurídicos de valoración fácilmente aplicables por todos los empleados de la compañía. En este entorno, a los clásicos negocios de los auditores, como la consultoría, la asesoría fiscal o la propia de revisión de las cuentas, se unen el asesoramiento en la aplicación de los criterios de valoración, el test de deterioro y otros requerimientos intrínsecamente establecidos en las normas contables.

Desde la entrada en vigor en España de la Ley 44/2002, es posible conocer en el Informe Anual de cada empresa, el importe facturado a cada cliente, distinguiendo auditoría y otros servicios. Con estos datos, afirmamos que las multinacionales auditoras realizan trabajos de auditoría, abogacía y consultoría jurídica y fiscal a un mismo cliente. Esta variedad de tareas, inicialmente prohibidas, está justificada porque los grupos multinacionales de auditoría han creado un entramado de diferentes sociedades, con personalidad jurídica autónoma, en la que cada una de ellas realiza un trabajo diferente al cliente. De esta forma, cada división, que es una persona jurídica, realiza una actividad y todas las divisiones de la multinacional ofrecen un servicio global e integrado.

Hay efectos perniciosos en la realización de diversas actividades por parte del auditor. "Es probable que la independencia de los auditores que prestan a sus clientes servicios masivos de auditoría se resienta, y ello por dos razones: de un lado, porque el temor a perder un cliente importante - es decir, un cliente del que se obtienen muchas cuasi-rentas particulares-invita a ser más complaciente; $y$, de otro, porque si como consultora le ha asesorado en campos tales como sistemas de información, diseño de programas de control, planning fiscal, servicios jurídicos, etc., como auditora le costará más trabajo revisar ciertas irregularidades que pueden tener su origen en las propias recomendaciones" (Paz-Ares, 1996, p. 107). A pesar de sus efectos, la doctrina no es partidaria de limitar la actividad. Cándido Paz-Ares (1996, p. 108) no propone la prohibición drástica de la realización de otras actividades, sino que recomienda otras actuaciones, como obligar a publicitar los ingresos obtenidos por ellas.

Los estudios empíricos han mostrado resultados contradictorios; mientras que Richard M. Frankel, Marilyn Johnson y Karen Nelson (2002) observan una relación de pérdida de independencia por ofrecer servicios adicionales a la auditoría, Hyeesoo Chung y Sanjay Kallapur (2003) no han encontrado evidencia entre proporcionar servicios de consultoría y una minoración en la independencia del auditor.

Independientemente de la opinión doctrinal y de los resultados empíricos, la fijación de incompatibilidades ha sido valorada como medida positiva por la mayoría de legislaciones internacionales, tanto porque puede dar buenos resultados, como porque es fácilmente aplicable. Las restricciones en la actuación han sido establecidas con diferente profundidad por cada legislación.

Los organismos estadounidenses, tanto SEC como AICPA, vienen defendiendo desde hace mucho tiempo la separación teórica de la auditoría y la consultoría. La SEC (2011) considera que la oferta de servicios adicionales perjudica la independencia del auditor, debido a la dependencia económica que genera, pues los auditores pueden ser más permisivos y tratar 
a los clientes de forma más favorable, para retener así a cada cliente y obtener en un futuro mayores ingresos de este. El mismo organismo apunta que la prestación de servicios adicionales implica que el auditor adopte un papel gerencial en diversas operaciones, siendo difícil que le ponga distancia a la dirección de la compañía y, además, se estaría auditando su propio trabajo. La limitación de actividad vigente en Estados Unidos está recogida en el artículo 201 de la Sarbanes-Oxley Act of 2002 (Committee on Financial Services, US House of Representatives, 2002), la cual enumera las actividades prohibidas a los auditores; entre ellas, destacan las valoraciones, servicios jurídicos y recursos humanos.

Los organismos reguladores de la UE no se ponen de acuerdo. La VIII Directiva aprobada el 17 de mayo de 2006 (Parlamento Europeo y Consejo de la UE, 2006) permite que se puedan realizar también otro tipo de servicios, siempre que el auditor legal reúna los requisitos de independencia. El artículo 22, apartado 2, de la Directiva 2006/43/CE propone una clara diferenciación entre los servicios de auditoría y los servicios adicionales, al señalar que no se deberían prestar servicios de auditoría en casos en los que "una tercera parte objetiva, razonable e informada pueda llegar a la conclusión de que la independencia del auditor legal o de la sociedad de auditoría está comprometida". La interpretación de este artículo ha sido muy diferente en los Estados miembros, por lo que el Libro Verde: Política de auditoría: lecciones de la crisis planteó la posibilidad de reforzar la prohibición de prestar servicios distintos de auditoría por parte de las sociedades de auditoría.
El informe Política de auditoría: lecciones de la crisis, aprobado por el Parlamento Europeo (2011), subraya que es probable que haya conflictos de intereses cuando las empresas auditoras ofrecen servicios diferentes a la misma empresa. El apartado 29 del texto del Parlamento Europeo concreta que los servicios de auditoría interna y externa no deben prestarse al mismo tiempo.

La postura del Parlamento Europeo rechaza la prohibición absoluta de prestar otros servicios, como se manifestaba en el dictamen inicial, y apunta a la elaboración de una "lista de las condiciones bajo las que dichos servicios se considerarán incompatibles con la auditoría”. Es más, el Parlamento Europeo reconoce que la prestación de esos servicios puede desarrollar un papel esencial para ampliar la capacidad de pequeñas y medianas firmas de auditoría.

La Propuesta de Reglamento del Parlamento Europeo y del Consejo sobre los requisitos específicos para la auditoría legal de las entidades de interés público (Comisión Europea, 2011a, artículo 15) establece que "el auditor legal o la sociedad de auditoría deberá ser independiente respecto de la entidad auditada y no participará en su proceso de toma de decisiones; no realizará ningún tipo de operación relacionada con instrumentos financieros que hayan sido emitidos, garantizados o de alguna otra forma apoyados por cualquier entidad auditada que pertenezca al ámbito de sus actividades de auditoría, salvo que se trate de participaciones en organismos de inversión colectiva diversificada, incluidos los fondos gestionados como, por ejemplo, fondos de pensiones y seguros de vida". 
En cuanto a la propuesta de la Comisión Europea de prohibir prestar otros servicios diferentes de la auditoría, el Parlamento Europeo la rechaza en su informe y apunta a la elaboración de una "lista de las condiciones bajo las que dichos servicios se considerarán incompatibles con la auditoría”. En otro orden de cosas, el Parlamento Europeo también reconoce que la prestación de esos servicios puede desempeñar un papel esencial para ampliar la capacidad de pequeñas y medianas firmas de auditoría.

Esta tibieza en la regulación comunitaria complica el entendimiento de las normas, tanto de forma directa, como su influencia sobre las normas nacionales.

En España, la Ley de Auditoría de Cuentas de 1988 (LAC) no aseguró suficientemente el principio de independencia con la limitación de actividad, al no prohibir que una misma sociedad o sociedades del mismo grupo prestasen a un mismo cliente los servicios de auditoría y de asesoramiento jurídico (fiscal, mercantil...).

La Ley 44/2002 amplió los supuestos de incompatibilidad ya existentes en el artículo 8.2 de la LAC: tener cargos directivos, de administración o supervisión, tener interés financiero directo o indirecto, consanguinidad o afinidad hasta el segundo grado con los empresarios, los administradores y los responsables del área económica-financiera de las empresas o entidades auditadas; preparación de los documentos contables de la entidad auditada; prestación al cliente de auditoría, de servicios, de diseño y puesta en práctica de sistemas de tecnología de la información, salvo determinadas circunstancias; prestación de servicios de valoración en cantidades significativa que conlleven un grado significativo de subjetividad; auditoría interna, salvo determinadas circunstancias; relación empresarial, a menos que se ajuste a la actividad empresarial normal y no sea significativa; servicios de abogacía "simultáneamente para el mismo cliente o para quienes lo hubiesen sido en los tres años precedentes, salvo que dichos servicios se prestasen por personas jurídicas distintas y con Consejos de Administración diferentes" (artículo 8.2.i de la LAC); participación en la contratación de altos directivos o personal clave para el cliente de la auditoría; y la percepción de honorarios conjuntos de auditoría y otros distintos de la auditoría a un único cliente, siempre que estos constituyan un porcentaje indebidamente elevado de los ingresos anuales del auditor de cuentas considerando la media de los últimos cinco años.

Además de lo anterior, la Ley 44/2002, de 22 de noviembre, en sus artículos 47 a 53 y en sus Disposiciones Adicionales novena, décima, undécima y decimocuarta, obliga a publicar en el Informe Anual los honorarios facturados a cada cliente, distinguiendo auditoría y otros servicios y a cualquier sociedad del grupo de sociedades a que pertenezca el auditor o con las que esté vinculado por propiedad común, gestión o control.

A este respecto, el Texto Refundido de la Ley de Auditoría de Cuentas introdujo en el artículo 21, Honorarios y transparencia en la remuneración de los auditores de cuentas y de las sociedades de auditoría, en su segundo apartado una novedad no incluida en la Ley 12/2010, "los auditores de cuentas y sociedades de auditoría deberán comunicar al Instituto de Contabilidad y Auditoría de Cuentas anualmente las 
horas y honorarios facturados a cada entidad auditada, distinguiendo las que corresponden a trabajos de auditoría de cuentas y otros servicios prestados, así como cualquier otra información que precise el Instituto de Contabilidad y Auditoría de Cuentas para el ejercicio de sus funciones".

El vigente artículo 8.3 de la Ley 12/2010, que coincide con el artículo 13 del Texto Refundido de la Ley de Auditoría, establece que:

En todo caso, se considerará que el auditor de cuentas o la sociedad de auditoría no goza de la suficiente independencia en el ejercicio de sus funciones respecto de una empresa o entidad, además de en los supuestos de incompatibilidad previstos en otras leyes, cuando concurra alguna de las siguientes circunstancias en el auditor de cuentas firmante del informe de auditoría:

a) La condición de cargo directivo o de administración, el desempeño de puestos de empleo o de supervisión interna en la entidad auditada, o el otorgamiento a su favor de apoderamientos con mandato general por la entidad auditada.

b) Tener interés financiero directo o indirecto en la entidad auditada si, en uno u otro caso, es significativo para cualquiera de las partes.

c) La existencia de vínculos de matrimonio, de consanguinidad o afinidad hasta el primer grado, o de consanguinidad colateral hasta el segundo grado, incluidos los cónyuges de aquellos con quienes mantengan estos últimos vínculos, con los empresarios, los administradores o los responsables del área económica-financiera de la entidad auditada.

d) La llevanza material o preparación de los estados financieros u otros documentos contables de la entidad auditada.

e) La prestación a la entidad auditada de servicios de valoración que conduzcan a la evaluación de cantidades significativas, medidas en términos de importancia relativa, en los estados financieros u otros documentos contables de dicha entidad correspondientes al período o ejercicio auditado, siempre que el trabajo de valoración conlleve un grado significativo de subjetividad.

f) La prestación de servicios de auditoría interna a la entidad auditada, salvo que el órgano de gestión de la empresa o entidad auditada sea responsable del sistema global de control interno, de la determinación del alcance, riesgo y frecuencia de los procedimientos de auditoría interna, de la consideración y ejecución de los resultados y recomendaciones proporcionados por la auditoría interna.

g) La prestación de servicios de abogacía para la entidad auditada, simultáneamente para el mismo cliente, salvo que esos servicios se presten por personas jurídicas distintas y con consejos de administración diferentes, y sin que puedan referirse a la resolución de litigios sobre cuestiones que puedan tener una incidencia significativa, medida en términos de importancia relativa, en los estados financieros correspondientes al período o ejercicio auditado. 
h) La percepción de honorarios derivados de la prestación de servicios de auditoría y distintos del de auditoría a la entidad auditada, siempre que estos constituyan un porcentaje significativo del total de los ingresos anuales del auditor de cuentas o sociedad de auditoría, considerando la media de los últimos tres años.

i) La prestación a un cliente de auditoría de servicios de diseño y puesta en práctica de sistemas de tecnología de la información financiera, utilizados para generar los datos integrantes de los estados financieros de dicho cliente, salvo que el cliente asuma la responsabilidad del sistema global de control interno o el servicio se preste siguiendo las especificaciones establecidas por el cliente, el cual debe asumir también la responsabilidad del diseño, ejecución, evaluación y funcionamiento del sistema.

La Ley 12/2010 presenta cuatro cambios respecto a la legislación precedente:

- Respecto a los servicios de valoración, se incorpora la referencia a la importancia relativa para medir si las cantidades valoradas son significativas y se especifica que deben serlo en relación al período auditado.

- Respecto a los servicios de abogacía, se añade la prohibición de prestación (incluso por persona jurídica distinta) si son referidos a la resolución de litigios sobre cuestiones que puedan tener incidencia significativa, medida en términos de importancia relativa, en el período auditado.
- Respecto a la percepción de honorarios por otros servicios, se modifica "porcentaje indebidamente elevado" por "porcentaje significativo" y el cómputo de 5 años para medirlo se pasa a 3 años.

- Se elimina (aunque siempre sujeto a la identificación de amenazas y salvaguardas) el mantenimiento de relaciones empresariales, la participación de contratación de altos directivos y la prestación por el socio firmante de otros servicios.

La verdadera razón de que las auditoras sigan realizando actividades, aunque es consensuado que podría menoscabar su independencia, es que suponen una enorme fuente de ingresos, incluso a veces mayores que los de la propia auditoría. Además, en nuestra opinión, si se consigue regular la exclusión de actividad es porque realmente a las multinacionales auditoras no les interesa hacerse cargo de esa tarea; esta idea puede ser observada en la normalización española para regular las valoraciones a fair value.

Las disposiciones adicionales novena, décima y undécima de la Ley 44/2002, y el artículo 8.3.e de la Ley 12/2010, con buen criterio, exigen que el auditor que realice la determinación del valor razonable debe ser un auditor nombrado por la sociedad o por el Registro Mercantil, pero siempre diferente al nombrado por la sociedad.

La Ley 44/2002, de 22 de noviembre, obliga a contratar otro auditor, y no se conforma con el cambio de equipo dentro de la firma, para hacer la valoración de fair value. De la redacción legal, podemos extraer que la razón para 
establecer esta exclusión de actividad es que la Ley 44/2002 considera que las actividades de valoración están prohibidas para el auditor de cuentas anuales porque afectan su independencia, con base en la incompatibilidad establecida en el artículo 8.2.f de la nueva redacción de la Ley de Auditoría de Cuentas. Esta opinión española es concordante con el artículo 10.g(3) de la SEC de 1934, introducida por el artículo de la Sarbanes-Oxley Act de 2002.

Si la verdadera razón fuera esta, no habría dudas de que los auditores no deben prestar servicios de asesoramiento y abogacía a sus auditados. Sin embargo, al afirmar la Ley que las actividades de valoración están prohibidas para el auditor, pero la consultoría y demás no, podemos suponer que la verdadera razón es otra. En realidad, las multinacionales auditoras no tenían interés en asumir estos servicios “(...) porque en la práctica sus clientes les presionarían para que, por los honorarios percibidos en concepto de la auditoría de cuentas, realizasen tales valoraciones" (Vicent-Chuliá, 2004, p. 207).

Por todo ello, para alcanzar la independencia, recomendamos separar la auditoría del resto de actividades, no solo las de apoyo al cálculo de los criterios de valoración.

\section{Limitación temporal}

El tercer medio institucional para preservar la independencia de los auditores de cuentas es la rotación obligatoria en el ejercicio de su cargo.

Hay opiniones favorables a limitar la relación cliente-auditor, pero también organismos, autores y estudios empíricos avalan la permanencia del auditor.
En contra de la rotación obligatoria ya estaban organismos como el Cohen Report (1945), y posteriormente opiniones doctrinales. Cándido Paz-Ares (1996, p. 105): “(...) No solo porque, al acortar la secuencia natural de las inversiones de arranque, eleva de manera sustancial los costes de la auditoría, sino también porque en absoluto garantiza una mejor calidad de la auditoría”. En la misma dirección, Benito Arruñada y Cándido Paz-Ares (1995, p. 31) defienden que la duración prolongada permite el ahorro de costes (que en gran medida son costes de arranque) y favorecen un mejor conocimiento del cliente, lo que evita que se produzcan efectos adversos sobre la competencia; además, los mismos autores afirman que la rotación obligatoria reduce la competencia en el mercado de la auditoría, estableciendo “(...) un sistema de turnos que divide artificialmente el mercado, minorando los incentivos de las firmas para invertir". Ambos argumentos, sin duda válidos, son problemas empresariales de los auditores, no argumentos contrarios a la consecución de la independencia.

Los estudios empíricos son contrarios al establecimiento de medidas de rotación. James N. Myers, Linda A. Myers y Thomas C. Omer (2003) y Aloke Ghosh y Doocheol Moon (2005) demostraron cómo una mayor duración está asociada a una mayor calidad del trabajo. Por su parte, Joseph V. Carcello y Albert L. Nagy (2004) no encontraron evidencia de que las situaciones de fraude contable sean más frecuentes cuando la rotación del auditor es menor.

La mayoría de las legislaciones establecen, de forma más o menos rigurosa, la rotación obligatoria. Sin embargo, en todas ellas se han 
generalizado varias excepciones legales que permiten el ejercicio de la actividad auditora en una empresa cliente durante muchos años.

Para incrementar la independencia, es imprescindible fijar una limitación temporal. Pero es necesario hacerlo de forma efectiva, no como se ha realizado en Estados Unidos y España para las cotizadas y las grandes sociedades. La Ley estadounidense Sarbanes-Oxley (Committee on Financial Services, US House of Representatives, 2002) no ha conseguido su objetivo de alcanzar una rotación obligatoria, ya que el artículo 203 solamente obliga a la rotación de los equipos de auditores, pero no a la firma de auditoría. En España, la Ley 44/2002 tampoco consigue unos niveles altos de independencia, porque solo exige la rotación del director del equipo de auditoría y de la totalidad de los miembros del equipo de auditoría, pero no de la firma. La Ley 12/2010 empeora la situación, porque obliga a que se cambie el auditor, pero no el equipo ni la firma. Este criterio es el que mantiene también el Texto Refundido, que entró en vigencia el 3 de julio de 2011.

En España, hasta 1995, hubo una rotación obligatoria. Transcurrido el plazo del nombramiento del auditor, el contrato cesaba y no podía realizar la actividad auditora en la sociedad: "Las personas que deben ejercer la auditoría de las cuentas serán nombradas por la junta general antes de que finalice el ejercicio por auditar, por un período de tiempo determinado, que no podrá ser inferior a tres años ni superior a nueve, a contar desde la fecha en que se inicie el primer ejercicio a auditar. No podrán ser reelegidas hasta que hayan transcurrido tres ejercicios desde la terminación del período an- terior" [Redacción del apartado 1 del artículo 204 Texto Refundido de la Ley de Sociedades Anónimas anterior a Ley 2/1995].

La Ley de Sociedades de Responsabilidad Limitada 2/1995 modificó los artículos 8 de la LAC y 204 del Texto Refundido de la Ley de Sociedades Anónimas, TRLSA, lo que permite que, agotado el plazo del primer nombramiento, el auditor pueda ser renovado indefinidamente por la sociedad auditada.

Más adelante, el artículo 51.1 de la Ley 44/2002, de 22 de noviembre, de Medidas de Reforma del Sistema Financiero, establecía que los auditores serán contratados por un período no inferior a tres años ni superior a nueve, pudiendo ser contratados anualmente una vez haya finalizado el período inicial.

El apartado 4 del artículo 8 de la LAC fue modificado de nuevo por la Ley 16/2007, de 4 de julio, de reforma y adaptación de la legislación mercantil en materia contable para su armonización internacional con base en la normativa de la Unión Europea, y quedó redactado en la actualidad de esta manera: "Los auditores serán contratados por un período inicial que no podrá ser inferior a tres años ni superior a nueve a contar desde la fecha en que se inicie el primer ejercicio a auditar, pudiendo ser contratados por períodos máximos de tres años una vez que haya finalizado el período inicial. Durante el período inicial, o antes de que finalice cada uno de los trabajos para los que fueron contratados una vez finalizado el período inicial, no podrá rescindirse el contrato sin que medie justa causa”. El vigente artículo 264.1 del Texto Refundido de la Ley de Sociedades de Capital, TRLSC, posee una redacción equivalente. 
Esta es la norma general para todas las sociedades anónimas. La Ley 44/2002, de 22 de noviembre, introduce una excepción que afecta únicamente a (a) las sociedades sometidas a supervisión pública, (b) las cotizadas y (c) las que tengan cifra de negocios superior a treinta millones de euros. El artículo 8.4 de la nueva redacción de la Ley de Auditoría de Cuentas dispone: “(...) una vez transcurridos siete años desde el contrato inicial, será obligatoria la rotación del auditor de cuentas responsable del trabajo y de la totalidad de los miembros del equipo de auditoría, debiendo transcurrir en todo caso un plazo de tres años para que dichas personas puedan volver a auditar a la entidad correspondiente (...) aunque no hubiesen cumplido durante algún período de tiempo alguna de las circunstancias mencionadas”. Esta regulación solo exige la rotación del auditor de cuentas responsable del trabajo y de la totalidad de los miembros del equipo de auditoría, pero no de la firma.

El vigente artículo 8 quáter de la Ley 12/2010 (art. 19 Proyecto Texto Refundido Ley de Auditoría de Cuentas) establece que "Los auditores serán contratados por un período de tiempo determinado inicial, que no podrá ser inferior a tres años ni superior a nueve a contar desde la fecha en que se inicie el primer ejercicio a auditar, pudiendo ser contratados por períodos máximos sucesivos de tres años una vez que haya finalizado el período inicial. Si a la finalización del período de contratación inicial o de prórroga del mismo, ni el auditor de cuentas o la sociedad de auditoría ni la entidad auditada manifestaren su voluntad en contrario, el contrato quedará tácitamente prorrogado por un plazo de tres años"... “Tratándose de entidades de interés público (EIP), o de sociedades cuyo importe neto de la cifra de negocios sea superior a 50 millones de euros, una vez transcurridos siete años desde el contrato inicial, será obligatoria la rotación del auditor de cuentas firmante del informe de auditoría, debiendo transcurrir en todo caso un plazo de dos años para que dicha persona pueda volver a auditar a la entidad correspondiente. Será obligatoria dicha rotación cuando en el séptimo año o, en su defecto, en los años siguientes, la entidad auditada tenga la condición de entidad de interés público o su importe neto de la cifra de negocios fuese superior a 50 millones de euros con independencia de que, durante el transcurso del referido plazo, la entidad objeto de auditoría de cuentas no hubiese cumplido durante algún período de tiempo alguna de las circunstancias mencionadas en este párrafo". Respecto a la legislación pretérita, la Ley 12/2010 mantiene, para EIP y superiores a 50 millones, la obligación de rotación a los siete años, pero ciñéndose al auditor firmante del informe, además, se reduce el período de descanso a 2 años.

Las últimas legislaciones comunitarias aprobadas, sobre las que había muchas esperanzas para que resolvieran la situación definitivamente, también han sido un fracaso. El pleno del Parlamento europeo aprobó, el 28 de septiembre de 2005, el texto definitivo de la Directiva sobre control de las firmas auditoras, que regula la actividad de los profesionales de la auditoría. La nueva ley establece la rotación obligatoria del socio auditor cada siete años. La llamada rotación externa, u obligación de que las empresas cambien periódicamente de firma audi- 
tora y no solo de socio, se valora positivamente, aunque se deja como opción para cada legislación nacional. El acuerdo final ha perdido así la ambición inicial; la Directiva lo reconoce expresamente en su artículo 52, al calificar el texto como "una armonización de mínimos" y autorizar a los Estados a "imponer normas más exigentes si lo desean”. Por otro lado, la VIII Directiva, aprobada el 17 de mayo de 2006, establece que la rotación obligatoria de siete años, se limite al socio auditor, sin que sea necesario que rote también la firma auditora.

El Libro Verde (Comisión Europea, 2010) establece la rotación obligatoria de la sociedad de auditoría cuando se cumplen unos determinados años y no solo de los socios auditores.

Por el contrario, el texto aprobado por el Parlamento Europeo (2011) reitera su opinión de que no es la rotación externa sino los cambios regulares de auditores lo que constituye la mejor solución reguladora, como está establecido en la Directiva 2006/43/CE. Se aboga por la rotación obligatoria de los socios principales de la auditoría, incluso si cambian de sociedad. En el documento finalmente aprobado se indica que la actual "rotación del socio proporciona la independencia necesaria para la efectividad de una auditoría”. Por ello, se descarta la rotación de la sociedad de auditoría. Incluso, el Parlamento Europeo señala en su informe que "la actual rotación del socio proporciona la independencia necesaria para la efectividad de una auditoría".

La Propuesta de Reglamento del Parlamento Europeo y del Consejo sobre los requisitos específicos para la auditoría legal de las entidades de interés público (Comisión Europea, 2011a, artículo 17) introdujo la rotación obligatoria. "Para reducir la amenaza de familiaridad, introduce la rotación obligatoria de las sociedades de auditoría al cabo de un plazo máximo de seis años. No obstante, si se realizan auditorías conjuntas, es decir, si la entidad auditada nombra a más de una sociedad de auditoría para llevar a cabo su auditoría, el período tras el cual se hace obligatoria la rotación puede ampliarse a nueve años. Se estipula también un período transitorio durante el cual la sociedad de auditoría no podrá volver a auditar a la misma entidad (al menos cuatro años).

El efecto de estas normalizaciones, tan variables y contradictorias, es que permiten que se perpetúen las relaciones entre la firma de auditoría y la entidad auditada.

La supresión de la rotación obligatoria tras los nueve años fue defendida con argumentos económicos, que ocultaban, en parte, la verdadera motivación para su defensa: el gran poder fáctico del grupo de presión de las grandes multinacionales auditoras.

La rotación obligatoria generaría un mecanismo de evaluación temporal de los auditores, es decir, los auditores entrantes controlarían el trabajo de las firmas salientes, por lo que los posibles fallos de auditoría no se perpetuarían indefinidamente.

Ante las deficiencias de la normativa española y el declarado fracaso de la normativa europea, podríamos pensar que la situación es complicada, sin embargo, la propia complejidad de la situación ofrece la solución. El artículo 52 de la Directiva sobre control de las firmas auditoras señala que el texto es una armonización de mínimos, por lo que se autoriza 
expresamente a los estados comunitarios que impongan normas más restrictivas, si así lo desean. En esta situación, la solución es que la legislación española instaure como obligatoria la rotación de la firma de auditoría para todo tipo de sociedades, no solo de la rotación de los equipos de auditores o del auditor responsable.

De las respuestas publicadas por la Comisión Europea sobre la consulta llevada a cabo a finales de 2010 a más de 700 miembros de la profesión, supervisores, inversores, académicos, autoridades públicas y asociaciones profesionales, sobre diversas cuestiones incluidas en el Libro Verde (Comisión Europea, 2010), se deduce que aspectos como la rotación obligatoria o la prohibición de prestación de servicios distintos a los de auditoría por las firmas auditoras, lejos de contribuir a mejorar el valor añadido de las auditorías, redundaría en una disminución de su calidad.

En concreto, sobre la rotación obligatoria, hay una oposición mayoritaria a la rotación obligatoria de las firmas de auditoría, principalmente por los perjuicios que esta medida puede tener para la calidad de la auditoría, así como por el incremento de los costes asociados.

En cuanto a la prestación de servicios distintos de los de auditoría se deduce que estos aumentan el conocimiento del auditor sobre la empresa y sobre la gestión de sus riesgos y, por tanto, aumentan la calidad del trabajo de auditoría. A la vez que se entiende que hay mecanismos de control suficientes para garantizar la independencia del auditor sin la necesidad de prohibir prestar estos servicios. Sin embargo, recomiendan la creación de una lista de servicios permitidos y servicios prohibidos.
En nuestra opinión, la cualidad más importante del auditor debe ser la independencia, por lo que el camino emprendido por la UE es incorrecto y cada vez, puede ser peor. La regulación debería establecer una rotación de firma (no es suficiente con que se cambie el equipo y se mantenga la firma) y de equipo (tampoco es suficiente el cambio de firma y que se mantenga el equipo). Es verdad que esta rotación completa o total aumentará el tiempo y el esfuerzo de las personas que los realiza, pero no es necesariamente cierto que aumentará los precios de la auditoría, mucho más cuando claramente hay cárteles de precios entre los proveedores de servicios de auditoría. Y aunque aumentara el precio, incrementaría el nivel de independencia, por lo que es necesario decidir qué nivel de independencia deseamos.

El Congreso estadounidense aprobó el 9 de julio de 2013, por 321 votos a 62, al anteproyecto de ley que prevé modificar la Sarbanes-Oxley Act of 2002, que obliga a la rotación de las firmas de auditores. Los argumentos mantenidos por quienes votaron a favor se resumen en que la rotación de los auditores aumenta los costes de auditoría, al tiempo que resiente la calidad de la auditoría.

La tendencia regulatoria de la SEC tiene visos de ser adoptada por la Unión Europea, UE. En la actualidad, la UE tramita un Reglamento que incluye la rotación, pero las diferencias son tan grandes entre Comisión, Parlamento y Consejo, que su aprobación es francamente difícil. La regulación estadounidense, con toda seguridad, se impondrá sobre el resto, por lo que es muy difícil que un texto comunitario imponga una rotación completa o total, que vaya en contra de lo establecido en aquel país. 


\section{Consecuencias finales}

La independencia real es imposible de observar en la práctica. Por esta razón, las definiciones de independencia establecidas en las legislaciones y organismos internacionales están centradas en buscar que la actuación parezca independiente, más incluso que en la búsqueda de ser independiente.

La independencia aparente y real está en sospecha en un entorno económico, como el actual, con una acusada concentración sectorial de las multinacionales auditoras.

Los problemas de independencia tienen su origen en las deficientes regulaciones estadounidense y europea, sin duda, debido a las presiones de las grandes auditorías internacionales. El camino de la SEC y de la regulación del Congreso estadounidense está equivocado. La de la UE es deficiente porque es equivocada y, además, depende de lo que esté establecido en Estados Unidos, y lo peor es que los diferentes organismos de la UE no se ponen de acuerdo.

Nuestra propuesta para mejorar la independencia de los auditores se basa en dos actuaciones. La primera es instaurar la rotación externa obligatoria total o completa (de firma y de equipo), para todo tipo de sociedades sin renovación en un plazo máximo de nueve años cambiando de firma auditora. Con esta medida se impide que la relación cliente-auditor se convierta en permanente, y al rotar se realiza una cierta revisión auditorauditor al terminar el plazo de nueve años. La legislación europea - o en todo caso, la legislación española-debe reinstaurar la regla de rotación externa obligatoria que no debió suprimirse. La rotación obligatoria debe ser de firma, no admitiéndose la rotación de los equipos de auditores o del director del equipo de auditoría, pero no de la firma de auditoría, como en Estados Unidos o en España para algunos tipos de sociedades. Pero también debe ser de equipo, de forma que tampoco sea suficiente el cambio de firma y que se mantenga el equipo.

La segunda es separar de forma total la auditoría del resto de los negocios ofrecidos a sus clientes. De esta forma, las auditoras podrán realizar servicios de valoraciones de los elementos registrados en contabilidad, de consultoría, de asesoramiento legal y de asesoramiento fiscal, pero no a las mismas empresas que realizan la auditoría.

Los recelos de los auditores a perder la relación contractual con los clientes actuales quedan compensados con las oportunidades de negocio que se abren con esta nueva situación; por un lado, podrían conseguir los clientes de otros auditores que terminen sus contratos; por el otro lado, podrían contratar el resto de servicios a clientes a los que no audite. Esta situación reforzaría las competencias en el mercado de la auditoría, lo que promovería la mejora en la eficiencia de los procesos.

El autor analiza de una manera descriptiva las exigencias establecidas en diferentes normativas europeas y españolas y eventualmente compara la regulación con lo requerido en Estados Unidos, lo cual aporta al entendimiento de la problemática actual sobre este asunto. 


\section{Referencias}

American Institute of Certified Public Accountants, AICPA (1996). Audits of Investment Companies, with conforming changes as of May 1 AICPA Audit and Accounting Guide. New York: AICPA.

Arruñada, Benito (1999). The Provision of Non-Audit Services by Auditors: Let the Market Evolve and Decide. International Review of Laws and Economics, 19 (4), 513-531.

Arruñada, Benito \& Paz-Ares, Cándido (1995). Mandatory Rotation of Company Auditors: A Critical Examination. International Review of Laws and Economics, 17, 31-61.

Carcello, Joseph V. \& Nagy, Albert L. (2004). Audit Firm Tenure and Fraudulent Financial Reporting. Auditing: A Journal of Practice \& Theory, 23, 55-69. Disponible en: http:// corpgovcenter.utk.edu/Research/AudFirmTenureCar2004.pdf

Chung, Hyeesoo \& Kallapur, Sanjay (2003). Client Important, Nonaudit Services and Abnormal Accruals. Accounting Review, 78, 931-955.

Cohen Report (1945). Report of the Committee on Company Law Amendment. London: His Majesty's Stationery Office. Disponible en: http://www.takeovers.gov.au/content/Resources/other_resources/Cohen_Committee.aspx

Committee on Financial Services, US House of Representatives (2002). Sarbanes-Oxley Act, 30 de julio de 2002. Disponible en: http://financialservices.house.gov/media/pdf/109-21.pdf, www.sarbanes-oxley. com
Cook, John W. \& Winkle, Gary M. (1987). Auditoría. México: Interamericana.

DeAngelo, Linda Elizabeth (1981). Auditor Size and Audit Quality. Journal of Accounting and Economics, 3 (3), 183-199.

Firth, Michael (2002). Auditor-Provided Consultancy Services and their Associations with Audit Opinions. Journal of Business Finance and Accounting, 29 (June-July), 661693.

Flint, David (1988). Philosophy and Principles of Auditing: An Introduction. London: MacMillan.

Frankel, Richard M.; Johnson, Marilyn \& Nelson, Karen (2002). The Relation between Auditor' Fees for Nonaudit Services and Earnings Management. Accounting Review, 77 suppl., 71-105.

García-Benau, María Antonia; Zorio-Grima, Ana \& Novejarque-Civera, Josefina (2013). Políticas europeas sobre auditoría en tiempos de crisis. Revista Galega de Economía, 22 (1), 229-248. Disponible en: http:/www.usc.es/ econo/RGE/Vol22_1/castelan/bt3c.pdf

Ghosh, Aloke \& Moon, Doocheol (2005). Auditor Tenure and Perceptions of Audit Quality. Accounting Review, 80, 586-612.

Gul, Ferdinand A. (1989). Bankers' Perceptions of Factors Affecting Auditor Independence. Journal of Accounting, Auditing and Accountancy, 2 (3), 40-51.

Instituto de Censores Jurados de Cuentas de España, ICJCE (2011). Resumen de respuestas al Libro Verde de la Comisión Europea: Política de auditoría: lecciones de la crisis.

Lindberg, Deborah L. \& Beck, Frank D. (2003). CPA's Perceptions of Auditor Independ- 
ence: An Analysis of Views Before and After the Collapse of Enron. Working Papers, Illinois State University, November 15, 2003. Disponible en: http://aaahq.org/audit/ midyear/03midyear/papers/AuditorIndeppaper1-AuditingSection.isu.pdf Marcelo, Eduardo; Tao, Zhang \& Moore, Billy Carl (2002). The Effect of the Enron Collapse on Investor Perceptions of Auditor Independence and Financial Statement Reliability. Working Papers, Illinois State University, July 10, 2002.

Myers, James N.; Myers, Linda A. \& Omer, Thomas C. (2003). Exploring the Term of the Auditor Client Relationship and the Quality of Earnings: A Case for Mandatory Auditor Rotation? Accounting Review, 78 (3), 779 800. Disponible en: file:///D:/Mis\%20 documentos/Downloads/Myerspart1c.pdf

Paz-Ares, Cándido (1996). La ley, el mercado y la independencia del auditor. Madrid: Civitas.

Ruddock, Caitlin; Taylor, Sarah \& Taylor, Stephen (2011). Non-Audit Services and Earnings Conservatism: Is Auditor Independence Impaired? University of Technology, Sidney, January.

Sahuquillo-Tudela, Carlos (2008). La independencia del auditor. XVIII Forum del Auditor Profesional, 3 de julio de 2008, Sitges.

Securities and Exchange Commission, SEC (2011). Revision of the Commission's Auditor Independence Requirements. Disponible en: www.sec.gov/rules/final/33-7919.htm

Stettler, Howard F. (1977). Auditing Principles. Englewood Cliffs, New Jersey: Prentice Hall.
Titard, Pierre L. (1971). Independence and MAS-Opinions of Financial Statement Users. The Journal of Accountancy, July, 47-52.

Vicent-Chuliá, Francisco (2004). Reforma contable y derecho mercantil. Revista de Contabilidad, 7 (1) (monográfico: La contabilidad en su contexto interdisciplinar), 161-211.

Watts, Ross L. \& Zimmerman, Jerold L. (1983). Agency Problems, Auditing and the Theory of the Firm: Some Evidence. Journal of Law and Economics, 26 (3), 613-633.

\section{Normativa}

\section{Española}

Ley 17, de julio de 1951 de Régimen Jurídico de las Sociedades Anónimas. Boletín Oficial del Estado, BOE, 199, 18 de julio de 1951. Corrección de errores Boletín Oficial del Estado, BOE, 218, 6 de agosto de 1951.

Ley 19/1988, de 12 de julio, de Auditoría de Cuentas (LAC). Disponible en: http://noticias.juridicas.com/base_datos/Derogadas/ r4-119-1988.html

Ley 24/1988 del Mercado de Valores, de 28 de julio de 1988. Boletín Oficial del Estado, BOE, 275, 29 de julio de 1988. Texto original: http://noticias.juridicas.com/base_datos/ Fiscal/124-1988.html. Texto consolidado: http://www.boe.es/buscar/pdf/1988/BOE-A1988-18764-consolidado.pdf

Ley 19/1989, de 25 de julio de Reforma Parcial

y Adaptación de la Legislación Mercantil a las Directivas de la Comunidad Económica Europea en materia de Sociedades. Boletín Oficial del Estado, BOE, 178, 27 de julio de 1989. Disponible en: http://www. 
boe.es/boe/dias/1989/07/27/pdfs/A2408524110.pdf, http://legislacion.derecho.com/ ley-19-1989-de-reforma-parcial-y-adaptacion-de-la-legislacion-mercantil-a-las-directivas-de-la-comunidad-economica-europeacee-en-materia-de-sociedades

Ley 2/1995, de 23 de marzo, de Sociedades de Responsabilidad Limitada. Boletín Oficial del Estado, BOE, 71, 24 de marzo de 1995. Disponible en: http://noticias.juridicas.com/base_ datos/Derogadas/r8-12-1995.html

Ley 37/1998, de 16 de noviembre, de Reforma de la Ley 24/1988 de 28 de julio del Mercado de Valores. Boletín Oficial del Estado, BOE, 275, de 17 de noviembre de 1998. Disponible en: http://noticias.juridicas.com/ base_datos/Fiscal/137-1998.html

Ley 44/2002, de 22 de noviembre, de Medidas de Reforma del Sistema Financiero. Boletín Oficial del Estado, BOE, 281, 23 de noviembre de 2002. Disponible en: http://www. boe.es/boe/dias/2002/11/23/pdfs/A4127341331.pdf

Ley 26/2003, de 17 de julio, por la que se modifica la Ley 24/1998, de 28 de julio, del Mercado de Valores, y el Texto Refundido de la Ley de Sociedades Anónimas, aprobado por el Real Decreto Legislativo 1564/1989, de 22 de diciembre, con la finalidad de reforzar la transparencia de las sociedades cotizadas. Boletín Oficial del Estado, BOE, 171, 18 de julio de 2003. Disponible en: http:// www.boe.es/boe/dias/2003/07/18/pdfs/ A28046-28052.pdf

Ley 16/2007, de 4 de julio, de reforma y adaptación de la legislación mercantil en materia contable para su armonización internacio- nal con base en la normativa de la Unión Europea. Boletín Oficial del Estado, BOE, 160, 05 de julio de 2007. Disponible en: http:// www.boe.es/boe/dias/2007/07/05/pdfs/ A29016-29047.pdf

Ley 12/2010, de 30 de junio, por la que se modifica la Ley 19/1988, de 12 de julio, de Auditoría de Cuentas, la Ley 24/1988, de 28 de julio, del Mercado de Valores y el texto refundido de la Ley de Sociedades Anónimas aprobado por el Real Decreto Legislativo 1564/1989, de 22 de diciembre, para su adaptación a la normativa comunitaria. Boletín Oficial del Estado, BOE, 159, jueves 1 de julio de 2010. Disponible en: http://noticias.juridicas.com/base_datos/Fiscal/1122010.html

Real Decreto Legislativo 1/2011, por el que se aprueba el Texto Refundido de la Ley de $\mathrm{Au}$ ditoría de Cuentas. Boletín Oficial del Estado, BOE, 157, 1 de julio de 2011. Disponible en: http://noticias.juridicas.com/base_datos/ Fiscal/rdleg1-2011.html

Real Decreto 302/1989, de 17 de marzo, por el que se aprueba el estatuto y la estructura orgánica del Instituto de Contabilidad y Auditoría de Cuentas, ICAC. Boletín Oficial del Estado, BOE, 77, 31 de marzo de 1989. Disponible en: http://www.minhap.gob.es/Documentacion/Publico/NormativaDoctrina/ Contabilidad\%20y\%20Auditoría\%20de\%20 Empresas/Contabilidad/EST.pdf

Real Decreto Legislativo 1564/1989, de 22 de diciembre por el que se aprueba el Texto Refundido de la Ley de Sociedades Anónimas. Boletín Oficial del Estado, BOE, 310, 27 de diciembre de 1989. Corrección de 
errores Boletín Oficial del Estado, BOE, 28, 1 de febrero de 1990. Disponible en: http:// www.boe.es/boe/dias/1989/12/27/pdfs/ A40012-40034.pdf, texto corregido: http:// boe.es/boe/dias/1990/02/01/pdfs/A0308303086.pdf

Real Decreto Legislativo 1564/1989, de 22 de diciembre, por el que se aprueba el Texto Refundido de la Ley de Sociedades Anónimas (TRLSA). Boletín Oficial del Estado, BOE, 310, 27 de diciembre de 1989. Disponible en: http://www.boe.es/boe/ dias/1989/12/27/pdfs/A40012-40034.pdf

Real Decreto 1636/1990, de 20 de diciembre, por el que se aprueba el Reglamento que desarrolla la Ley 19/1988, de 12 de julio, de Auditoría de Cuentas (RLAC). Boletín Oficial del Estado, BOE, 308, 25 de diciembre de 1990. Disponible en: http://www.boe.es/boe/ dias/1990/12/25/pdfs/A38447-38455.pdf

Real Decreto 1643/1990, de 20 de diciembre, por el que se aprueba el Plan General de Contabilidad. Boletín Oficial del Estado, BOE, 310, 27 de diciembre de 1990. Corrección de errores Boletín Oficial del Estado, BOE, 63, 14 de marzo de 1991. Disponible en: http:// noticias.juridicas.com/base_datos/Fiscal/ rd1643-1990.html, texto corregido: http:// www.boe.es/boe/dias/1991/03/14/pdfs/ A08433-08434.pdf

Real Decreto 1784/1996, de 19 de julio, por el que se aprueba el Reglamento del Registro Mercantil. Boletín Oficial del Estado, BOE, 184, 31 de julio de 1996. Disponible en: http://noticias.juridicas.com/base_datos/ Privado/rd1784-1996.html
Real Decreto 1784/2000, de 27 de octubre, por el que se modifica el Real Decreto 302/1989, de 17 de marzo, por el que se aprueba el Estatuto y la estructura orgánica del Instituto de Contabilidad y Auditoría de Cuentas, ICAC. Boletín Oficial del Estado, BOE, 259, 28 de octubre de 2000. Disponible en: http://www.boe.es/boe/ dias/2000/10/28/pdfs/A37487-37488.pdf

Real Decreto Legislativo 1/2010, de 2 de julio, por el que se aprueba el texto refundido de la Ley de Sociedades de Capital. Boletín Oficial del Estado, BOE, 161, 3 de julio de 2010. Disponible en: http://noticias.juridicas. com/base_datos/Privado/rdleg1-2010.html

Resolución de 19 de enero de 1991, del Instituto de Contabilidad y Auditoría de Cuentas, por la que se publican las Normas Técnicas de Auditoría. Disponible en: http://www. icac.meh.es/Temp/20140501231841.pdf

\section{Unión Europea}

Comisión Europea (2002). Recomendación de la Comisión de 16 de mayo de 2002. Independencia de los auditores de cuentas en la UE: principios fundamentales. Diario Oficial de las Comunidades Europeas, DOCE, L 191, de 19 de julio de 2002. Bruselas: Comisión Europea. Disponible en: http://portaljuridico.lexnova.es/legislacion/ JURIDICO/95861/recomendacion-2002590-ce-de-la-comision-de-16-de-mayo-de2002-independencia-de-los-auditores-de-c Comisión Europea (2004). Comunicación de la Comisión al Consejo y al Parlamento Europeo, de 27 de septiembre de 2004, sobre la prevención y la lucha contra las prácticas irregulares 
empresariales y financieras [COM (2004) 611 final]. Bruselas: Comisión Europea.

Comisión Europea (2008a). Recomendación de la Comisión, de 6 de mayo de 2008, relativa al control de calidad externo de los auditores legales y las sociedades de auditoría que verifican las cuentas de las entidades de interés público (2008/362/CE). Diario Oficial de la Unión Europea, L 120, de 07 de mayo de 2008. Bruselas: Comisión Europea. Disponible en: http://portaljuridico. lexnova.es/legislacion/JURIDICO/95866/ recomendacion-de-la-comision-de-6-demayo-de-2008-relativa-al-control-de-calidad-externo-de-los-aud

Comisión Europea (2008b). Recomendación de la Comisión, de 5 de junio de 2008, sobre la limitación de la responsabilidad civil de los auditores legales y las sociedades de auditoría. Diario Oficial de la Unión Europea, L 162, de 21 de junio de 2008. Bruselas: Comisión Europea. Disponible en: http://www.boe.es/ doue/2008/162/L00039-00040.pdf

Comisión Europea (2008c). Decisión de la Comisión, de 29 de julio de 2008, por la que se establece un período transitorio para las actividades de los auditores y las sociedades de auditoría de algunos países terceros (2008/627/CE). Diario Oficial de la Unión Europea, L 202, de 30 de julio de 2008. Bruselas: Comisión Europea. Disponible en: http://portaljuridico.lexnova.es/legislacion/ JURIDICO/82260/decision-de-la-comisionde-29-de-julio-de-2008-por-la-que-se-establece-un-periodo-transitorio-para

Comisión Europea (2008d). Comunicación de la Comisión al Consejo Europeo, de 26 de noviembre de 2008, denominada Un plan europeo de recuperación económica [COM (2008) 800 final]. Bruselas: Comisión Europea. Disponible en: http:// eur-lex.europa.eu/legal-content/ES/ ALL/?uri=CELEX:52008DC0800

Comisión Europea (2010). Libro Verde. Política de auditoría: lecciones de la crisis. [COM (2010) 561 final, de 13 de octubre de 2010]. Bruselas: Comisión Europea. Disponible en: http://eur-lex.europa.eu/legal-content/ ES/ALL/?uri=CELEX:52010DC0561

Comisión Europea (2011a). Propuesta de Reglamento del Parlamento Europeo y del Consejo sobre los requisitos específicos para la auditoría legal de las entidades de interés público [COM (2011) 779 final, de 30 de noviembre de 2011]. Bruselas: Parlamento Europeo/Consejo de la Unión Europea. Disponible en: http:// eur-lex.europa.eu/legal-content/ES/ ALL/?uri=CELEX:52011PC0779

Comisión Europea (2011b). Propuesta de Directiva del Parlamento Europeo y del Consejo por la que se modifica la Directiva 2006/43/CE, relativa a la auditoría legal de las cuentas anuales y de las cuentas consolidadas [COM (2011) 778 final, de 30 de noviembre de 2011]. Bruselas: Parlamento Europeo/Consejo de la Unión Europea. Disponible en: http://ec.europa.eu/internal_market/auditing/docs/reform/directive_es.pdf

Comisión de las Comunidades Europeas (1998). Comunicación de la Comisión relativa a la auditoría legal de la Unión Europea: el camino a seguir. Diario Oficial de las 
Comunidades Europeas, DOUE, C 143, 8 de mayo de 1998.

Comisión de las Comunidades Europeas (2003). Comunicación de la Comisión al Consejo y al Parlamento europeo-Refuerzo de la auditoría legal en la UE. Diario Oficial de las Comunidades Europeas, DOUE, C 236, 2 de octubre de 2003.

Comité Económico y Social Europeo, CESE (2011). Dictamen del Comité Económico y Social Europeo sobre el Libro Verde. Política de auditoría: lecciones de la crisis. [COM (2010) 561 final]. Diario Oficial de la Unión Europea, C 248, 25 de agosto de 2011. Bruselas: Comité Económico y Social Europeo. Disponible en: http://eurlex.europa.eu/LexUriServ/LexUriServ. do?uri=COM:2010:0561:FIN:ES:PDF

Consejo de la Unión Europea (1984). Directiva 84/253/CEE del Consejo, de 10 de abril de 1984, basada en la letra g) del apartado 3 del artículo 54 del Tratado CEE, relativa a la autorización de las personas encargadas del control legal de documentos contables. Diario Oficial de las Comunidades Europeas, L 126, 12 de mayo de 1984. Bruselas: Consejo de la Unión Europea. Disponible en: http://eur-lex.europa.eu/legal-content/ES/ TXT/?uri=CELEX:31984L0253

Parlamento Europeo (2011). Resolución del Parlamento Europeo, de 13 de septiembre de 2011, sobre Política de auditoría: lecciones de la crisis. Bruselas: Parlamento Europeo. Disponible en: http://www. europarl.europa.eu/sides/getDoc. do?pubRef=-//EP//TEXT+TA+P7-TA-20110359+0+DOC+XML+V0//ES

Parlamento Europeo; Consejo de la Unión Europea (2006). Directiva 2006/43/CE del Parlamento Europeo y del Consejo de 17 de mayo de 2006, relativa a la auditoría legal de las cuentas anuales y de las cuentas consolidadas, por la que se modifican las Directivas 78/660/CEE y 83/349/CEE del Consejo y se deroga la Directiva 84/253/ CEE del Consejo. Diario Oficial de la Unión Europea, L 157, 9 de junio de 2006. Bruselas: Parlamento Europeo/Consejo de la Unión Europea. Disponible en: http://eurlex.europa.eu/legal-content/ES/TXT/PDF/? uri=CELEX:32006L0043\&from $=\mathrm{ES}$

- Fecha de recepción: 29 de agosto de 2013

- Fecha de aceptación: 13 de marzo de 2014

\section{Para citar este artículo}

Villacorta-Hernández, Miguel Ángel (2014). Abandono legislativo del objetivo de alcanzar la independencia en la auditoría de cuentas. Cuadernos de Contabilidad, 15 (37), 215-237. 
